\title{
Review on Constraints, Opportunities Traditional Coping Mechanism of Milk Marketing Participation in Ethiopia
}

\author{
HAILE TAMIRU (MSc)
}

\begin{abstract}
The major species used for milk production in Ethiopia are cattle, camel and cows which produce $83 \%$ of the total milk and $97 \%$ of the cow milk comes from indigenous cattle breeds. The key development issues in dairy are low average milk productivity complicated by widespread food insecurity, growing gap between supply and demand in urban areas. Federal Cooperatives Commission of Ethiopia was created to organize and promote cooperatives at the national level and it ambitious five year development plan (2005-2010) to increasing the share of the cooperative input marketing and increasing the share in cooperative output marketing. Small-scale milk producers face many hidden costs that make it difficult for them to gain access to markets and productive assets. The relatively high marketing costs for milk in Ethiopia, the scattered nature milk markets and the risk attached to marketing of perishables in the tropics suggest that transaction costs play a central role in dairy production and marketing. Transaction costs are also the embodiment barriers to market participation by resource-poor smallholders. Milk groups allows them to share information, encourage one another in the business, build trust with the producers, reduce the transaction costs of monitoring, and can easily be reached by the regulators. They sometimes share contracts with sellers and buyers when there is more demand or supply.
\end{abstract}

DOI: $10.7176 / \mathrm{JMCR} / 69-01$

Publication date:July $31^{\text {st }} 2020$

\section{INTRODUCTION}

Background of the study

Ethiopia's poverty-stricken economy is based on agriculture, accounting for half of GDP, (CSA, 2007)The sector is essentially composed of smallholders, as $63 \%$ of the farmers cultivate less than 1 hectare, and $87 \%$ less than 2 hectares (Ethiopian Economic Association 2004/5). Subsistence agriculture accounts for the most part as it is estimated that roughly $30 \%$ of agricultural production is marketed. Over the past decade, the Federal government of Ethiopia has taken important steps in promoting cooperatives (a form of RPOs) as a means to connect smallholders to markets (Berhane and Workneh, 2003 ).

According to CSA (2007) report in Ethiopia the livestock sub-sector is estimated to contribute about $12-16 \%$ of the total GDP and 30-35\% of total agricultural GDP and 60-70\% livelihoods of the Ethiopia population. Also this agency report that the major Livestock population in Ethiopia is estimated to be 39,714, 653 cattle, 14, 326, 206 sheep and 11,155, 218 goat. Of these resources, $20 \%$ of cattle and $25 \%$ of sheep are found in the lowland pastoral areas of the country. The estimated annual growth rates are $1.2 \%$ for cattle, $1 \%$ for sheep and $0.5 \%$ for goats (CSA, 2007). The major species used for milk production in Ethiopia are cattle, camel and goats. Cattle produce $83 \%$ of the total milk and $97 \%$ of the cow milk comes from indigenous cattle breeds. The total population of animals used for milk production is $13,632,161 \mathrm{TLU}$. Although milk production is increasing by $1.2 \%$ per annum, the demand-supply variance for fresh milk is ever widening and the per capita consumption is diminishing (Aklilu et.al, 2002).

The key development issues in dairy are low milk production complicated by widespread food insecurity, growing gap between supply and demand in urban areas, and low average milk productivity (Adina and Elisabeth, 2006). The total value of the export of livestock and livestock products has been increasing over time. During the last ten years, the total value increased from Birr 408 million (47 million USD) in 1997 to over one billion (121 million USD) in 2006. The trend of the export value of livestock has shown a rise during the last four years. The livestock sector ranks second to coffee in generating foreign exchange with the average official share of about 14 percent in the value of total export over the period 1985/86 - 2005/06 (NBE data base) (Debrah and Berhanu , 1991).

Small-scale milk producers face many hidden costs that make it difficult for them to gain access to markets and productive assets. The relatively high marketing costs for fluid milk in Africa, the scattered nature of fluid milk markets and the risk attached to marketing of perishables in the tropics suggest that transaction costs play a central role in dairy production and marketing (Bavikar, 1988).

Transaction costs are the embodiment barriers to market participation by resource-poor small-holders. They include the costs of searching for the partner with whom to exchange, screening potential trading partners to ascertain their trustworthiness, bargaining with potential trading partners (and officials) to reach an agreement to see that its conditions are fulfilled, and enforcing the exchange agreement (Holloway et al , 2000). Getting together with others also can allow individuals to better cope with risks, particularly when neither the private sector nor the government provides any "safety nets" or insurance against risk (Place et al, 2002) 
These milk groups allows them to share information, encourage one another in the business, build trust with the producers, reduce the transaction costs of monitoring, and can easily be reached by the regulators. They sometimes share contracts with sellers and buyers when there is more demand or supply. They also teach those new to the business how to manage it. Producers build trust with them such that one trader cannot default payment of a farmer's milk or cheat on them e.g. claiming that the milk got spoiled or never sold it. This is because the traders do the business together and monitor each other (Bellemare and Barrett., 2006).

Generally, farmers' milk marketing participation is important to improve the livestock product in all aspects. Also it is important to increase smallholders' income through improving market chain. Even though, different research have been done on nature, performance and determinant of milk market chain, market supply as well as value chain in different part of Ethiopia. But none of these researches did not give attention to determinants of milk marketing participation. Due to this fact, in view of the above statements the review is interested to focus on the determinants of smallholder farmer's participation in milk marketing in Ethiopia. Therefore, the specific objectives of this review paper are:

To review the challenges and opportunities of milk marking participation

To highlight policy implication to focus on further implementation to improve milk and milk product marketing in Ethiopia

\section{LITERATURE REVIEW}

\subsection{Empirical Review}

\subsubsection{Overview of dairy production systems in Ethiopia}

As defined by Gizachew (2005) livestock production systems are considered a subset of the farming systems, including cases in which livestock contribute more than $10 \%$ to total farm output in value terms or where intermediate contributions such as animal traction or manure represent more than $10 \%$ of the total value of purchased inputs. There are different classification criteria for livestock production systems in general and dairy production systems in particular. For example, based on criteria such as integration with crops, relation to land, agro-ecological zones, intensity of production and type of product, the world livestock production systems are classified into 11 systems (Jaffee, 1994). Of these livestock production systems, mixed farm rain fed temperate and tropical highlands (MRT system) is by far the largest. Globally, it represents $41 \%$ of the arable land, $21 \%$ of the cattle population, and $37 \%$ of dairy cattle (Belachew and Jemberu, 2003).

According to ZiaUllah, Shumaila and Muhammad, (2014) report Pakistan dairy sector contributed a very important role in the growth of nationwide economy and its value of contributions is more than wheat and cotton sectors combined. In fact Pakistan livestock sector contributed 55.4\% to the agricultural value added and about $11.9 \%$ to the gross domestic product (GDP) during fiscal year 2012-13. Milk production contributes in the livelihood, nutrition, and food security. Although world milk production derived from goats, sheep, buffaloes, cows and camels. These are the major species in the Pakistan to producing milk. In the overall world milk production comprises the shares of cows $83 \%$, buffaloes $13 \%$, goats $2 \%$, sheep $1 \%$ and camels contribution are $0.3 \%$. Pakistan livestock population is presented in Table. 1

According to John and Shahran (1998) report, dairying is practiced almost all over Ethiopia involving a vast number of small or medium or large-sized, subsistence or market-oriented farms. Based on climate, land holdings and integration with crop production as criterion, dairy production systems are recognized in Ethiopia; namely the rural dairy system which is part of the subsistence farming system and includes pastoralists, agro-pastoralists, and mixed crop-livestock producers; the peri-urban; and urban dairy systems (Azage and Alemu , 1998)

According to Muriuki and Thorpe (2001) idea, the first system (pastoralism, agro pastoralism and highland mixed smallholder production system) contributes to $98 \%$, while the per-urban and urban dairy farms produce only $2 \%$ of the total milk production of the country. Rahel( 2009), the rural system is non-market oriented and most of the milk produced in this system is retained for home consumption. The level of milk surplus is determined by the demand for milk by the household and its neighbors', the potential to produce milk in terms of herd size and production season, and access to a nearby market. According to ideas of above author, surplus is mainly processed using traditional technologies and the processed milk products such as butter and sour milk are usually marketed through the informal market after the households satisfy their needs. Fekadu,(1994) suugested that Pastoralists raise about $30 \%$ of the indigenous livestock population which serve as the major milk production system for an estimated $10 \%$ of the country's human population living in the lowland areas. Milk production in this system is characterized by low yield and seasonal availability (Thorpe and Muriuk, 2001).

The highland smallholder milk production is found in the central part of Ethiopia where dairying is nearly always part of the subsistence, smallholder mixed crop and livestock farming. Local animals raised in this system generally have low performance with average age at first calving of 53 months, average calving intervals of 25 months and average lactation yield of 524 liters (Zegeye 2003). Per-urban milk production is developed in areas where the population density is high and agricultural land is shrinking due to urbanization around big cities like Addis Ababa. It possesses animal types ranging from $50 \%$ crosses to high grade Friesian in small to medium-sized 
farms. The per-urban milk system includes smallholder and commercial dairy farmers in the proximity of Addis Ababa and other regional towns. This sector owns most of the country's improved dairy stock (Tsehay 2001).

The main source of feed is both home produced or purchased hay; and the primary objective is to get additional cash income from milk sale. This production system is now expanding in the highlands among mixed crop-livestock farmers, such as those found in Selale and Holetta, and serves as the major milk supplier to the urban market (Ike, 2002), urban dairy farming is a system involving highly specialized, state or businessmen owned farms, which are mainly concentrated in major cities of the country. They have no access to grazing land. Currently, a number of smallholder and commercial dairy farms are emerging mainly in the urban and peri-urban areas of the capital ( (Azage and Alemu , 1998)) and most regional towns and districts (Ike, 2002)

Smallholder rural dairy farms are also increasing in number in areas where there is market access. According to Azage and Alemu (1998), the urban milk system in Addis Ababa consists of 5167 small, medium and large dairy farms producing 34.65 million liters of milk annually. Of the total urban milk production, $73 \%$ is sold, $10 \%$ is left for household consumption, 9.4\% goes to calves and $7.6 \%$ is processed into butter and ayib (cheese). In terms of marketing, $71 \%$ of the producers sell milk directly to consumers (Lemma, Fikadu and Hegde , 2004)

\subsection{Challenges and opportunities of Milk and milk product marketing in Ethiopia}

According to Gelila(2017), report s it was the situation of pastoral dairy production system, urban dairying is constrained by many factors that affect the quantity of milk produced as well as quality and safety of milk and milk products in the milk value chain. According to the ideas of above author, as ranked by the stockholder milk producing households, shortage of animal feeds $(26 \%)$ is the most important limiting factor of dairy production followed by limited space for proper housing, milking, waste disposal, and expansion (23\%), and animal disease incidence (18\%). Other important constraints include limited access to clean water, lack of improved dairy breeds and limited market outlet for milk ( GebreWold, Azage and Alemu, 1997).

Generally, Sintayehu et.al (2008) suggested that forage is the main charge of a given dairy farm. Dairy producers in different part of country reported that animal forage price raises frequently and there is narrow access to forage and these are key problems that hamper dairying in in the country supports this statement. Also according ideas of above, availability and cost of forages, difficulties associated to poor animal health services were common dairying constraints reported for urban producers. Besides, most urban producers keep their cattle within their own residence compound (Sintayehu et.al, 2008). Sintayehu et.al(2008) also reports lack of adequate land for proper housing, milking, and farm expansion have been considered as one of the important challenges to produce good quality milk in urban dairy production unlike the rural and per- urban areas. Allocation and giving place for efficiently farming dairy producers in different part of the country with clean water and well-organized management can play a significant role for quality milk production (Getachew, 2001)

\subsubsection{Challenges of milk marketing}

According to Yonad (2009) report, Seasonality of demand is the main challenges in dairy sector. The demand for milk and dairy products is very much affected by seasonal fall of demand among the Orthodox Christians (that comprise about half of Ethiopians population) during the fasting season and the fasting days. AccordingYonad the majority of the Orthodox Christians practice fasting more than 200 days per year, during which time they abstain from consuming animal products. When dairy enterprises process only pasteurized milk with a short shelf life, this means that processed volumes go down during the time when people (fast) consume less (Alemayehu, Hoekstra and Tegegne, 2012)

Emebet and Zeleke (2008) reported other conistraints of milk products, this conistraint animal health problem. According ideas of those authors, poor animal health and management are major constraints of dairy development in Ethiopia which cause poor performance across all dairy production systems. Many of these problems result from the interaction among constraints themselves e.g. poorly fed animals develop low disease resistance, fertility problem, partly because the animal health care system relies heavily on veterinary measure. Ketema (2000) explain Poor grazing management systems continue to cause high mortality and morbidity.

Feed and nutrition: Inadequate supply of quality feed is the major factors limiting dairy productivity in Ethiopia. Improved feeding is crucial to provide satisfactory environment for animal growth and feed supplements stimulate higher milk productivity. Feed, usually based on fodder and grass, are either not available in sufficient quantities due to fluctuating weather conditions or when available are of poor nutritional quality. These constraints result in low milk yields, high mortality of young stock, longer parturition intervals, and low animal weights.

Low productivity and genetics: The productivity of indigenous stock is a major constraint in dairy development. In the indigenous herds genetic potential for milk production is low. However, there is still a potential for increased production through improved management; selection of the best animals; improved reproduction; etc. Similarly, the Review on the Challenges and Opportunities of Dairy Value Chain Development in Ethiopia potential for production of marketable milk is not fully exploited in the indigenous herd. The selection of efficient breeds specifically adapted to respond to those elements in the environment that are subject to man ${ }^{\text {ee }}$ control is the necessary step to improve the dairy sector. 
Quality problem: Adulteration is the major problem in processing and marketing. Milk adulteration is usually done by farmers and brokers. Both hygienic and nutritional aspects are important in milk quality. It is important to identify where adulteration in particular occur in the marketing chain: - farmer level, middlemen, distribution.

Collection problems: Delays in collecting milk from the farmers to the processing plants and in delivering from the processors to the distributors contribute to high incidences of spoilage. Poor customer care coupled with unreliable and unhygienic processing methods contributed to poor product quality which in turn suggests the need to strengthen management and investment in udder hygiene and cold chain technologies. The use substandard milk collecting utensils and buckets for up lifting the milk from the supply centers, where many smallholders are doing their sells, may result in poor milk quality. Similarly, non-existence of chilling and cooling center at potential milk producing and supply area also cause a deterioration of milk quality.

Lack of infrastructures: Infrastructures, especially access roads that reach the rural community has limited the supply of marketable milk to collection centers. Even if farmers have the capacity to produce more milk than they are doing today, they are not encouraged to make effort on milk production they cannot sell. On top of inconvenient infrastructures the milk collection centers are not at the level of what they should be and needs special attention at different sites.

Lack of access to land: perhaps the greatest institutional and socio-economic constraint that the dairy industry faces today arises out of socio-economic rather than technical problems; i.e. the lack of access to land for expansion of the dairy enterprises and feed production. The problem of inadequate feed is a result of the limited land availability for pasture establishment especially on productive highland areas where dairy cattle can flourish and where the density of the population is high. There is no extension to supply information about technologies to improve production and marketing to estimate certain development. A shift towards a developed dairy industry requires more support from advisory services and more effective links with research services. Moreover, the structure and performance of livestock and its products including dairy products marketing both for domestic consumption and for export is generally perceived poor in Ethiopia (Ayele et al. 2003 and Betela, 2015)

Table 1.

\begin{tabular}{|c|c|c|c|c|c|c|c|c|}
\hline \multirow{2}{*}{ Constraints } & \multicolumn{6}{|c|}{ Limitation of dairy production } & \multirow{2}{*}{\multicolumn{2}{|c|}{$\begin{array}{l}\text { Weighted average } \\
\text { rank }\end{array}$}} \\
\hline & $1^{\text {st }}$ & $2^{\text {nd }}$ & $3^{\text {rd }}$ & $4^{\text {th }}$ & $5^{\text {th }}$ & $6^{\text {th }}$ & & \\
\hline Availability of forage & 62 & 55 & 12 & 3 & - & - & 0.23 & \\
\hline $\begin{array}{l}\text { Shortage of land for } \\
\text { expansion }\end{array}$ & 59 & 32 & 21 & 8 & 5 & 5 & 0.18 & \\
\hline Diseases prevalence & 4 & 24 & 51 & 34 & 16 & 2 & 0.14 & \\
\hline Absence of clean water & 1 & 12 & 25 & 54 & 31 & 7 & 0.12 & \\
\hline Lack of improve breed & 6 & 8 & 16 & 17 & 69 & 12 & 0.07 & \\
\hline Limited market access & - & 1 & 6 & 12 & 8 & 102 & 1.00 & \\
\hline
\end{tabular}

From the above table any one can understand that

\subsubsection{Opportunities of milk marketing in Ethiopia}

The bulky cattle population, the favorable climate for better, high yielding animal types and the comparatively disease-free environment for livestock make Ethiopia to have a significant potential for dairy development. Considering the important prospective for smallholder income generation and employment opportunities from the high value dairy products, the development of the dairy sector can contribute immensely to poverty alleviation and improved nutrition in the country. With the present trend characterized by transition towards a market-oriented economy, the dairy sector appears to be moving towards a takeoff stage. Liberalized markets, involvement of the private sector and promotion of smallholder dairy are the main features of this stage (Ahmed et.al, 2004)

The dairy industry is essential for rural Ethiopia and it is potentially the largest rural employer in the Ethiopian highlands and pastoral/ agro-pastoral areas. With continued urbanization, growing population size, demand for milk by the children and younger generation, it is expected that the dairy industry will become a major player in agricultural development and has further potential to contribute significantly towards increased income and employment.

According to report of SNV (2008); the following are opportunities of value chain Ethiopia dairy sectors at different level:- At the production level include equipment supply and leasing, farm input supplies via organized check-off systems for groups of large farmers, milk testing and recording services, transport services and private extension services. At the farm level, investment potential lies in medium and large dairy farming but also there is potential in food processing and provision of advisory services including breeding technologies. There is opportunities to invest in dairy feed processing and feed technologies. Within the processing and packaging component, emerging opportunities include investment in modern processing equipment, supply of processing inputs and packaging, equipment supply and leasing and marketing support services.

A number of existing small and medium scale dairy processors have limited capacity in terms of financial 
capital, equipment, technology and/or expertise. Some of such firms are interested in joint venture with other private investors local or foreigner to expand their operations. Similarly, some of the existing companies are also seeking for equity participation from foreign companies and individuals while others are considering outright purchase. With the relative fast growth registered in the dairy industry, there is a need to establish firms that provide dairy industry and related support services. Such services include artificial insemination; farm input supplies and market information, establishment of collection centers and distribution facilities, dairy breeding and farming. Post-harvest milk loose are high, especially during the peak seasons, when production level is high. This is due to limited access to milk collection centers. So far only the Sebeta Agro-industry and the LAME Dairy (formerly known as DDE) have limited number of milk collection centers.

The other private and cooperative firms lack collection centers and facilities. In addition, substantial amounts of milk are spoiled in transit. This is due to the substandard containers and mode of transport used to collect and transport milk from up to $100 \mathrm{~km}$ distance which lead to delays and high temperature build up in the milk. Thus, investment opportunities exist in establishing more and better managed milk collection centre as well as reliable milk distribution facilities including transport facilities and cold chains. Establishment of dairy breeding farms is another investment opportunity that is not yet fully exploited. Ethiopia has adequate land for dairy farming and the climatic conditions are favorable for this venture. A well-established dairy farm would produce milk and also breed in-calf heifers for sale. With the growth registered in the dairy industry, the demand for in-calf heifers is expected to increase. On the domestic market, the cost of an in-calf heifer ranges between Birr 7000 and Birr 12000. Currently most of the heifers on sale are cross breeds type reproduced with in the country. Most of them do not have records of pedigree and production. They are sold for their color (black and white) rather than level of performance

\subsubsection{Traditional milk handling and processing practices in Ethiopia}

Cows are the main source of milk, and it is cows' milk that is the focus of processing in Ethiopia (Yonad, 2009). Dairy processing in Ethiopia is generally based on ergo (fermented milk in Ethiopia), without any defined starter culture, with natural starter culture. Raw milk is either kept at ambient temperature or kept in a warm place to ferment prior to processing (Azage and Alemu , 1998). Dairy processing in the country is basically limited to smallholder level and hygienic qualities of products are generally poor and account about $52 \%$ of smallholder producers and 58\% of large-scale producers used common towel to clean the udder (Bellemare and Barrett., 2006).

In a study conducted in the Borena region of Ethiopia, butter was found to be an important source of energy as food for humans, and is used for cooking and as a cosmetic. The storage stability of butter, while not comparable to ghee, is still in the order of four to six weeks. This gives butter a distinct advantage over fresh milk in terms of more temporal flexibility for household use and marketing (Adina and Elisabeth, 2006)

Traditional milk technologies have evolved produce butter, whey and cottage cheese. However, traditional processing technologies are generally considered to be time consuming and inefficient in terms of milk fat recovery, product quality, a comparatively short shelf life and provide little return for the milk producer. Milk producers should follow hygienic practices during milking and handling before delivery to consumers or processors or for collection. Possible sources of post-harvest losses are scale of contamination affected by temperature and storage time, adulteration, lack of proper handling, transportation and distribution, low level of technology used to process milk to an acceptable standard and the lack of fresh milk outlets (Debrah and Berhanu , 1991).

The traditional smallholder dairy system makes up the largest part of the dairy production system and can be characterized by its low input, feeding and management requirement and use of indigenous genotypes. The improved dairy production system could be classified into small scale production systems, and commercial private urban and per urban production. The characteristics of the improved dairy production systems vary substantially in terms of intensification, management systems, genotypes used, type and methods of marketing and processing of milk and dairy products. At present this sector is expanding rapidly through intensification and expansion of smallholder milk production (Azage and Alemu , 1998)

\subsubsection{Dairy marketing systems in Ethiopia}

In the African context, markets for agricultural products would normally refer to market places (open spaces where commodities are traded). Conceptually, however, a market can be visualized as a process in which ownership of goods is transferred from sellers to buyers who may be final consumers or intermediaries. Therefore, markets involve sales, locations, sellers, buyers and transactions (Debrah and Berhanu , 1991).

\subsubsection{Formal vs. informal dairy marketing}

The term 'informal' is often used to describe marketing systems in which governments do not intervene substantially in marketing. Such marketing systems are also referred to as parallel markets. The term 'formal' is thus used to describe government (official) marketing systems (Debrah, 1990). Dependable system has not been developed to market milk and milk products in Ethiopia (Asfaw, 2009)Fresh milk is distributed through the informal and formal marketing systems. In both rural and urban parts of the country, milk is distributed from producers through the informal (traditional) means. This informal market involves direct delivery of fresh milk by 
producers to consumers in the immediate neighborhood or to any interested individuals in nearby towns (Debrah and Berhanu , 1991)

ZiaUllah, Shumaila and Muhammad (2014) study reveals that,initial intervention to promote formal dairy marketing started with the establishment of a 300 dairy farm and a small milk processing plant under the UN Relief and Rehabilitation Program in 1947 in the premises of the now Dairy Development Enterprise (DDE) ( (Sintayehu et.al, 2008). The same report stated that in 1959 UNICEF helped establish a processing plant with a processing capacity of 10 thousand liters per day with milk collection and purchasing centers around Addis Ababa. The radius of milk collection was later expanded to $70 \mathrm{~km}$ around the capital. Capacity of the processing plant was increased to 30 thousand liters in 1969. In 1979 the DDA (Dairy Development Agency) was transformed to the DDE when processing capacity was increased to 60 thousand liters/day and the radius of collection expanded to $150 \mathrm{~km}$ with donor assistance (Million and Tadelle , 2003).

Asfaw (2009) report sows that informal milk marketing system dominates the supply of milk and dairy products to consumers in Ethiopia. Also Muruiki et.al ( 2001) suggested, strategy for inclusion of the informal sector in dairy sub-sector development is vital for its sustainable development. The strategy to be employed includes organization of the stakeholders in production and marketing by stratification of the country into the different dairy production system and introduction of appropriate technologies to increase the efficiency of the dairy sector through reduction of post-harvest losses and improvement of quality (Yigezu, 2000).

\subsubsection{Role of farmers' dairy production in Economy}

According to ZiaUllah, Shumaila and Muhammad ( 2014) report on dairy sector plays a very significant role in the development of national economy and its value of contributions is more than wheat and cotton sectors combined. According to above author report, Pakistan cattle sector contributed $55.4 \%$ to the agricultural value added and about $11.9 \%$ to the gross domestic product (GDP) during fiscal year 2012-13. Milk production contributes in the livelihood, nutrition, and food security. Although world milk production derived from goats, sheep, buffaloes, cows and camels. These are the major species in the Pakistan to producing milk. In the overall world milk production comprises the shares of cows $83 \%$, buffaloes $13 \%$, goats $2 \%$, sheep $1 \%$ and camels contribution are $0.3 \%$. Pakistan livestock population is presented in Table. 1

According to (Debrah, 1990) report, milk-marketing group can be defined as a group of smallholder farmers who actually produce at least one liters of saleable milk and are willing to form a group with the objective of collectively processing and marketing milk. According to Berhane and Workneh (2003) report, to facilitate milk marketing by smallholders with crossbred cows, SDDP catalyzed the formation of producer 'milk groups' (also called 'milk units' or 'mini-dairies') to process milk into butter, local cottage-type cheese, and yoghurt-like sour milk (ergo), primarily in the northern zone and north of Addis Ababa (Nicholson et al., 1998).

\subsubsection{Role of dairy cooperatives in facilitating marketing}

According to (Chukwu, 1990) the international cooperative alliance, a cooperative is an association of persons united voluntarily to meet their common economic, social and cultural needs and aspirations through a jointly owned and democratically manage the same. It is a body organize to ensure self-help through mutual help, it is an association of persons who have joined together to fulfill individual needs in a democratic decision making organization in which all members participate and have a proportion of gain and losses. Also according to (Dawit, 2005) report, final goal of all cooperatives activity is to free men and women from social and economic burdens by enabling them to work for and through their fellow beings to uplift their social economic status. It is to make men with a sense of both individual and joint responsibility so that they rise individually, to a full personal life and collectively to a full social life. Cooperative is a useful tool for promotion or enhancing economic development. The cooperative movement plays an important role in establishing economic structures, making people aware of improvements and also utilizes improved techniques ( (Berhane and Workneh, 2003 ).

DFID (2010) suggested that, greatest asset of the movement of the economic development is great, mobilization power. Cooperative appeal to the self-interest of the masses in a way they can understand, and demonstrate with tangible results, that most of the economic problems facing a community can be solved by making use of the locally available resources and that people working together in a spirit of mutual help can improve the economic position no matter how hopeless and helpless it may seem (FAO, 2010). Cooperative philosophy enunciates those virtues that guide cooperative practices everywhere. It is an epitome of volunteers, cooperation, self-help, mutual, self-respect and social responsibility (Tesfaye, 2006).

Berhane and Workneh ( 2003 ), in their review, indicated the very useful involvement of the government of India at every step of the development for expansion of dairy cooperatives in the country for the successes of dairying and suggested that the pattern of dairy development (India) can be rivaled at least around the major milk sheds in Ethiopia, for instance around Nazareth, Dire Dawa, Harar, Bahir Dar, Gondar, Awassa (one of the present study areas), Jimma and Assela. As explained by Dawit ( 2005) demonstrated in India, dairy marketing cooperatives could provide farmers with continuous milk outlets, and easy access to essential inputs such as artificial insemination (AI), veterinary services and formulated feeds. Dairy cooperatives are supposed to help to trigger a series of positive developments in the subsector; hence strengthening the existing group marketing 
activities and formation of new cooperatives in different parts of the country (Berhane and Workneh , 2003 )

Hajela (2000) reported that, history of the dairy cooperative system in India began in 1946 with the establishment of the Milk Union Ltd (AMUL). In 1970, Operation Flood commenced with the objective of establishing a cooperative structure on the and pattern. In 1980, some 12 thousand village cooperative milk producers' societies had been established in 27 selected milk shed districts. This was expanded by 1984 to 28,174 village producers in 155 milk shed districts linked to markets in 147 towns. The case of Uganda (followed the same milk collection schemes through cooperatives with this regard) is also a good example from east Africa (MoARD., 2004)

Anroand (2009) report on cooperative selling institutions is potential catalysts for mitigating costs, stimulate smallholders' entry into the market, and promote growth in rural communities (Holloway.et.al, 2002). Case studies from Kenya and Ethiopia illustrate the role of dairy cooperatives in reducing transaction costs (Chukwu, 1990) A good example to be mentioned in Ethiopia is Ada'a-Liben Woreda Dairy Association (Azage and Alemu , 1998)which presently renders milk to processing plants in Addis Ababa.

YONAD (2009) reported that, Ethiopia has the potential and opportunities to start milk cooperatives, farmers have not yet risen to the occasion. According to this author, the development of milk cooperatives in the Oromia region with one Dairy Union is worth mentioning. The milk cooperatives are collecting and marketing the milk from farmers. The Cooperatives are trying to supply cattle feed to the farmers. They face the problem of marketing during the fasting months. They need to go a long way in procurement of milk on quality and quantity basis, processing of milk in to milk products like powder, butter, cheese, ghee, standardized and pasteurized milk, and marketing the same in their own outlets (Aklilu et.al, 2002).

\subsubsection{Common challenges of dairy production and marketing in Ethiopia}

Challenges and problems for dairying vary from one production system to another and/or from one location to another. The structure and performance of livestock and its products marketing both for domestic consumption and for export is generally perceived poor in Ethiopia. Underdevelopment and lack of market-oriented production, lack of adequate information on livestock resources, inadequate permanent trade routes and other facilities like feeds, water, holding grounds, lack or non-provision of transport, ineffectiveness and inadequate infrastructural and institutional set-ups, prevalence of diseases, illegal trade and inadequate market information (internal and external) are generally mentioned as some of the major reasons for the poor performance of this sector (Belachew and Jemberu, 2003)

In the debate of poverty reduction or small-scale vs. industrial production and in spite of a general consensus on the appropriateness of general recommendations, there seem to be a lack of vision regarding the future structure and roles of the present small-scale producers. Many donors seem ready to protect and preserve the smallholders, but few have a vision of the process requiring 'transforming small-scale subsistence producers into commercial producers supplying a modern, demanding food market' (DFID, 2010).

\subsection{Market Participation by Smallholders, milk-groups and Dairy Cooperatives}

Holloway.et.al (2002) surveys result shown that many potential liquid milk-marketing households are hours distant away from any milk group. Setting up new groups would clearly reduce the travel time to group, and the actual number of households that would benefit depends on local population densities. It is also important to keep newly emerging milk groups small and geographically limited to ensure proximity and avoid large groups that would tend to increase average travel times (Holloway et al., 2002). Another study showed that the creation of new market outlet for fluid milk brought major improvements in the production, marketing and consumption behavior of smallholder households. The new marketing outlet may also promote involvement in more intensive dairying (Nicholson, 2000). Co-operatives, by providing bulking and bargaining services, increase outlet market access and help farmers avoid the hazard of being encumbered with a perishable product with no rural demand ( (Jaffee, 1994)). In short, participatory co-operatives are very helpful in overcoming access barriers to assets, information, services, and the markets within which small-holders wish to produce high-value items (Jaffee, 1994)

Azage and Alemu (1998) reported about dairy development along the cooperative lines was considered to be the most effective strategy for helping the rural poor without altering the village social structure and providing guaranteed market for milk at fixed prices, supply of cattle feed at a reasonable cost and efficient veterinary and extension services (Bavikar, 1988). These are self-organized groups, which involve women who have milking cows and/or camels. They are locally called "Somaal' which means owners of milking animals. The number of women that participate in Milk marketing in Jijiga ranges from 2 to 5 per group.

Tadesse (2000) Members are organized on the basis of selling whole fresh cow and/or camel milk. In milk marketing group, members contribute an agreed amount of milk on a weekly basis and this is allocated to an individual woman on a shift basis. The woman sells the milk and the daily income belongs to her. The cycle continues until every member gets her share of the milk income. Women's access to and control of income has increased their social and economic autonomy as well as enhanced their participation in decision-making.

Pastoralist Somali women for example can influence migratory routes by pressuring men to locate camping 
sites near a small town, water source or a trading center, in order to maximize returns from their milk and milk products. Additionally, they take part in management decisions related to improving milk output. They may use some of their income to purchase supplementary feed for the livestock, and remain responsible for milking and hence directly able to determine the level of milk off-take (Michael, 1990).

YONAD (2009) the links between gender and participation in milk marketing activities are quite significant in this context. While women groups' relationships constitute the backbone of the network, male-managed transport facilities in the milk-routes represent the cornerstone of the system. In some cases milk car owners seem to take over the major functions and responsibilities from women groups as the system grows or as particular conditions of hardship developed. Also Ngigi (2005) have write about the collection of milk at one site by milk group is the driving force that put car owners to involve in the system. In pastoral community, butter tends to be made only when there is a surplus of milk from household requirements.

Yonad, (2009) also explained about production is constrained by the availability of female labour and so it depends on the ability of households to migrate seasonally in mass to the wet season pastures. (Randolf and Ndung'u , 2006) have wrote about Somali women in Jijiga, Babile and other small towns sell cow and camel milk in group to consumers. Milk is highly perishable, and yoghurt goes sour after several days. If there are no buyers then women have no choice but to give unsold stocks to their families before they spoil (Getachew, 2001).

\section{Marketing channels}

According to (Lemma, Fikadu and Hegde , 2004)report, analysis of dairy marketing networks is expected to deliver a efficient awareness of the movement of dairy and its yields from their production regions to their final consumer. In due course, it permits shortening the multifaceted nature of the subsector, helps to identify all key actors and the main leverage points for the sub-sector where targeted involvements could affect the entire value chain.

According to ideas of above authors, analysis of evidence gained from different sources during the study shows that there are five key market networks for fresh milk produced in Limu-Bilbilo district with which it reaches to final consumers (Figure 11). The end users of dairy products in the study area are single users and hotels/cafeterias of Assasa, Bekoji and Adama towns.

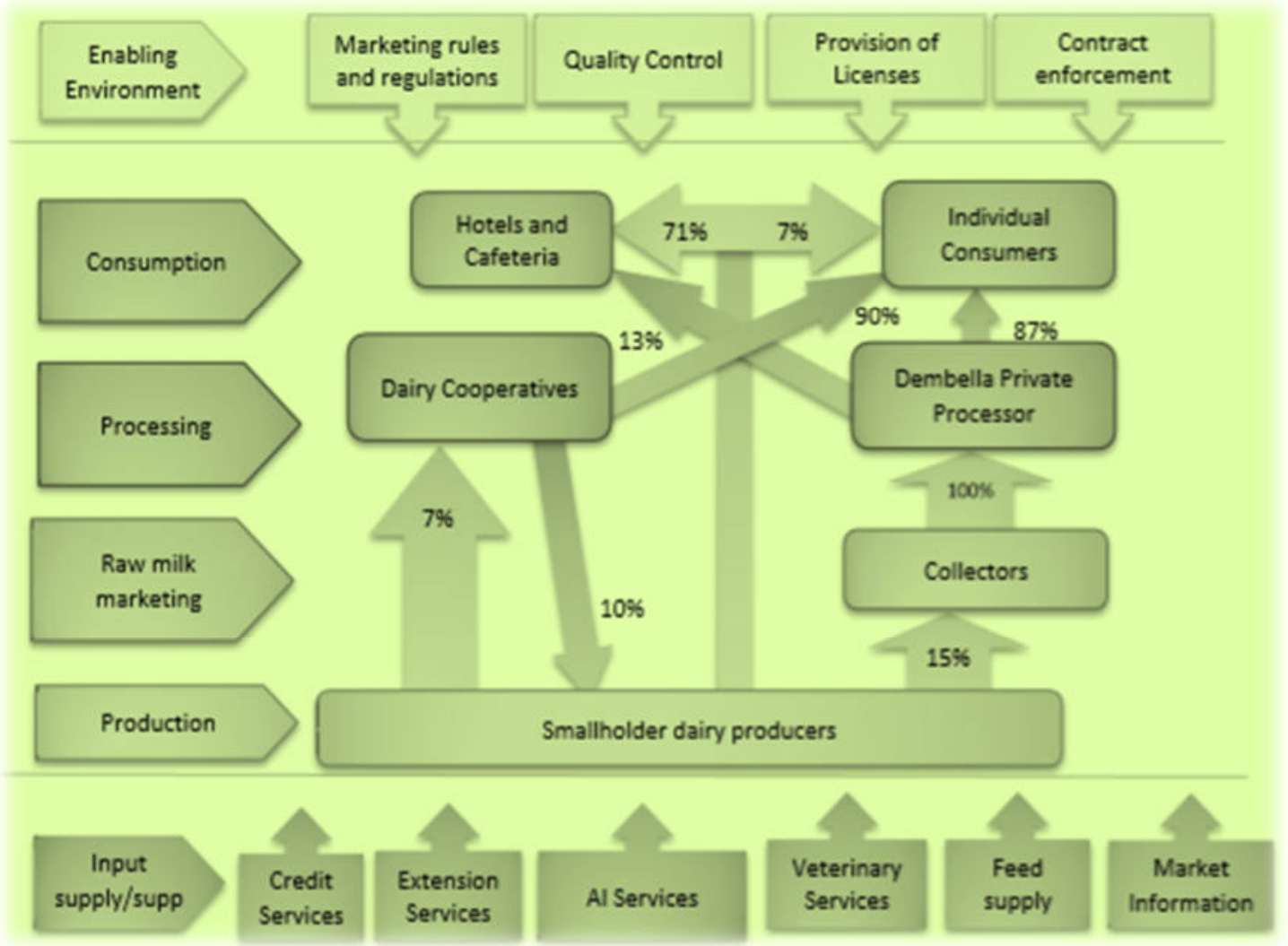

Fig.1. (Lemma , Fikadu and Hegde , 2004)

\section{Conclusion}

Review is focused on determinants of small holder farmers' participation in milk marketing to identify factors 
influencing participation in milk marketing and to suggesting recommendation for improving participation of small holders in milk marketing. Experience in dairying has a positive influence on participation in milk marketing because the if the household heads is more experienced he would be able manage more with activities of milk marketing. Number of children in school has positive association and significant level. Small stock ownership has association with the participation of the household heads in milk marketing and significant at exactly level at significance. Grain production has positive influence on participation of smallholders in milk marketing and the mount of loan received has negative association but significant at the level. Dairy production has positive relationship with the dependent variable and it significant significance more he produce more he will participate and less production causes less participation. Distance to the nearest market has negative relationship with the dependent variable and statistically insignificant at both levels.

Challenges and problems for dairying vary from one production system to another and/or from one location to another. Women's access to and control of income has increased their social and economic autonomy as well as enhanced their participation in decision-making. While women groups' relationships constitute the backbone of the network, male-managed transport facilities in the milk-routes represent the cornerstone of the system. Pastoral livestock and milk marketing cooperatives that could benefit from credit facilities and the procurement of livestock production inputs. These groups may also promote savings culture of pastoral communities for capital investment. The new marketing outlet may also promote involvement in more intensive dairying.

\section{Acknowledgements}

The authors wish to acknowledge Bule Hora University for providing internet service to collect different material for this Article review. The critical review and comments offered by Dr. Zelalem Ayana and was acknowledged. The assistance given from by Mr. Bayisa Bussa to collect the literature from different source is acknowledged. Personal profile

Mr Haile Tamiru Urgessa was graduate by Masters of Science in Agricultural Economics from wollega University in 2016. And employed in Bule Hora University as a lecturer and still serving as instructor and head department of Agricultural Economics

\section{Reference}

Adina and Elisabeth. (2006). Pastoralist livelihoods InitiativeLivestock Value Chain Analysis Report for Afar and Northern Somali Regions of Ethiopia.

Ahmed et.al. (2004). Dairy development in Ethiopia. EPTD Discussion paper No. 123. International Food Policy Research Institute. Washington, U.S.A. .

Aklilu et.al. (2002). An Audit of the Livestock Marketing Status Kenya Ethiopia, and Sudan. Vol.1. CommunityBased Animal Health \& Epidemiology (CAPE) Unit, African Union/Inter-African Bureau for Animal Resources (AU-IBAR).Nairobi, .

Alemayehu, Hoekstra and Tegegne. (2012). Smallholder dairy value chain development: The case of Ada"a woreda, Oromia Region, Ethiopia. Nairobi: ILRI.

Anroand, M. (2009). EnhancingFarmersEntrepreneurship,Creang condition for Growth, in magazine on low External Input and Sustainable Agriculture (LEISA).25(2)pp 6-8.The Netherlands.

Asfaw. (2009). Improving smallholder farmers' marketed supply and market access for dairy products in Arsi Zone, Ethiopia. Research Report 21. Nairobi: ILRI. .

Azage and Alemu . (1998). Prospects for peri-urban dairy development in Ethiopia. In: Fifth national conference of ESAP (Ethiopian Society of Animal Production). ESAP, Addis Ababa, Ethio.

Bavikar. (1988). Dairy Cooperatives and Rural Development in Gujarat, in D.W. Attwood and B.S. Bavikar (Eds). 1988, Who Shares? Cooperatives and Rural Development, Oxford University Press, Delhi. 56p. .

Belachew and Jemberu. (2003). Challenges and opportunities of livestock marketing in Ethiopia. In: Jobre Y and Gebru G (eds), Challenges and opportunities of livestock market.

Bellemare and Barrett. (2006). An Ordered Tobit Model of Market Participation: Evidence from Kenya and Ethiopia." American Journal of Agricultural Economics 88(20):324-.

Berhane and Workneh . (2003). Promotion of dairy marketing using farmer's cooperatives: Lessons from India.

Chukwu. (1990). Economics of the cooperatives business enterprise, Marburg, Germany.

CSA. (2007). Population and housing census report, Ethiopia. .

Dawit, A. (2005). The status and challenges of agricultural marketing in Ethiopia, Melkassa Agricultural Research Center, EARO Paper presented at a pane.

Debrah. (1990). Dairy marketing by intra-urban, peri-urban and rural dairy producers near Addis Ababa, Ethiopia. In: Brokken RF and Senait Seyoum (eds), Dairy marketing in sub-Saharan Africa: .

Debrah and Berhanu . (1991). Dairy marketing in Ethiopia: Markets of first sale and producer's marketing patterns. ILCA Research Report 19. ILCA (International Livestock Center for Africa), Addis Ababa, Ethiopia. $21 p$. 
DFID. (2010). Working with Cooperatives for Poverty Reduction', Briefing Note, UK Department for International Development, London.

Emebet and Zeleke . (2008). Characteristics and constraints of crossbred dairy cattle production in lowland areas of Eastern Ethiopia. Livest. Res. Rural Dev., 20(4): 7.

FAO. (2010). profitability and sustainability of agricultural cooperative, agricultural management, marketing and finance occasional paper No.19.

Fekadu. (1994). Present situation and future aspects of milk production, milk handling and processing of dairy products in Southern Ethiopia, (PhD thesis, Agricultural University of Norway).

GebreWold, Azage and Alemu. (1997). Prospects for peri-urban milk development in Ethiopia. In: Proceedings of 5th National Conference of Ethiopian Society of Animal Production (ESAP), 15-17 1997, Addis Ababa. Ethiopia, pp 248, 1998.

Gelila Ashenafi. (2017). Challenges and opportunities of milk production under different urban dairy farm sizes in Ethiopia .

Getachew. (2001). The Ethiopian Dairy Development Policy: A Draft Policy Document. Ministry of Agriculture, Addis Ababa, Ethiopia.

Gizachew. (2005). Dairy Marketing Patterns and Efficiency: The Case of Ada' Liben District, eastern Oromia. M.Sc. Thesis presented to Alemaya University, Ethiopia.

Hajela. (2000). cooperation: principles, problems \& practice. New Delhi: Konark Publishers Pvt. Ltd Oromia Cooperative Promotion Bureau (2010). Annual Report, unpublished Addis Ababa, Ethiopia.

Holloway.et.al. (2002). Expanding market participation among smallholder livestock producers.

Ike. (2002). Urban dairying in Awassa, Ethiopia. M.Sc thesis, University of Hohenheim, Institute of Animal production in the tropics and sub tropics, Stuttgart- Hohenheim, Germany p. 113. .

Jaffee. (1994). Perishable profits: Private sector Dairy processing and Marketing in Kenya. In: Jaffee S. and Morton J. (eds.), Marketing Africa's high-valued foods: Comparative experience of an emergent private sector. Kendall-Hunt, Dubuque,. Iowa, U.

Jaffee. (1994). Perishable profits: Private sector Dairy processing and Marketing in Kenya. In: Jaffee S. and Morton J. (eds.), Marketing Africa's high-valued foods: Comparative experience of an emergent private sector. Kendall-Hunt, Dubuque,. Iowa, U.

John and Shahran. (1998). Livestock and Meat marketing. Third edition.

Ketema. (2000). Dairy development in Ethiopia. In: The role of village dairyco-operatives in dairy development. SDDP (Smallholder Dairy Development Project) Proceedings, MOA (Ministry of Agriculture), Addis Ababa, Ethiopia. .

Lemma , Fikadu and Hegde . (2004). Traditional milk and milk products handling practices and preservation methods in three districts of East Shoa Zone of Oromia. In: Proceedings of the 12th Annual conference of the Ethiopian Society of Animal Production .

Million and Tadelle . (2003). Milk production performance of Zebu, Holstein Friesian and their crosses in Ethiopia. Livestock Research for Rural Development (15) 3. .

MoARD. (2004). Market-Oriented Development Master Plan.

Muriuki and Thorpe. (2001). Smallholder Dairy Production and Marketing. Constraints and Opportunities. P. Smith. Princeton,, 206-247p. New Jersey: Princeton University Press.

Muruiki et.al . (2001). Development of smallholder dairy systems in Kenya highlands Oromia pastoral areas land using planning study (Unpublished and on-going study) .

Ngigi. (2005). The Case of Smallholder Dairying in Eastern Africa, EPTD Discussion Papers 131, International Food Policy Research Institute (IFPRI). .

Nicholson. (2000). Producer milk groups in Ethiopia's highlands: A framework for assessing impacts and a review of group performance.

Rahel. (2009). Traditional and improved milk and milk products handling practices and compositional and microbial quality of milk and buttermilk in Delbo watershed of Wolayta zone, Ethiopia. Department of Animal and Range Sciences, College of Agriculture.

Randolf and Ndung'u . (2006). Gender and transaction costs: a conjoint analysis of choice of livestock health services among smallholder dairying Kenya. Paper presented at the XXIVth conference of the IAAE, August 18-24, Berlin. .

Sintayehu et.al. (2008). Dairy production, processing and marketing systems of Shashemene-Dilla area, South Ethiopia. IPMS (Improving Productivity and Market Success) of Ethiopian Farmers Project Working Paper 9. ILRI, Int. Lives.

SNV. (2008). Netherlands Development Organization Study on Dairy Investment Opportunities in Ethiopia, .

Tadesse. (2000). Status of Dairy Research in Ethiopia: In the Role of Village Dairy Cooperative in Dairy Development. Smallholder Dairy Development Project (SDDP) Proceeding, Ministry of Agriculture. Addis Ababa, Ethiopia. 
Tesfaye. (2006). Factors affecting the development of agricultural cooperatives in Ethiopia: A case study of Kilinto ASC, Ambo District, Oromia Region. Unpublished. Thesis for the partial fulfillment of the degree of master of arts, submitted to Ad.

Thorpe and Muriuk. (2001). Smallholder Dairy Production and Marketing. Constraints and Opportunities. P. Smith. Princeton, New Jersey: Princeton University Press, 206-247p.

Yigezu. (2000). Dairy Development Experience in milk collection, processing and marketing. In: The role of village dairy co-operatives in dairy development. Smallholder Dairy Development Project (SDDP) Proceeding. Addis Ababa, Ethiopia: Ministry of A.

Yonad. (2009). Value chain Analysis of Milk and Milk products in Borana pastoralist area, unpublished manuscript. 2009. [.

ZiaUllah, Shumaila and Muhammad . (2014). Dairy Supply Chain Management and Critical an Investigations on Dairy Informal Channel Partners in Pakistan . 